\title{
A Comparative Study on Moon Imagery in Chinese and Western Classical Poetry
}

\author{
Ding $\mathrm{Shi}^{1},{ }^{*}$ Jing $\mathrm{An}^{2}$
}

\author{
${ }^{1}$ Moonshot Academy \\ ${ }^{2}$ University of California, Santa Barbara \\ *Jing An. Email: jingan@ucsb.edu
}

\begin{abstract}
As essential imagery in Chinese and Western poetry, the moon imagery has high academic research value. However, few studies have compared the moon imagery in Chinese and Western poetry from the perspective of comparative literature. This article uses literature analysis and comparison method to compare and analyze the moon imagery in classic Chinese and Western poems from four aspects: connotation and theme of the moon imagery, poetry expression techniques, rhetorical devices, and language characteristics. Furthermore, the study discusses the cultural and literary reasons for the difference in the moon imagery. The study serves to understand better and compare the differences between Chinese and Western literature and culture and provides some insights for cultural communication and comparison.
\end{abstract}

Keywords: Moon Imagery, Classic Poetry, Comparative Literature, Chinese and Western Culture

\section{INTRODUCTION}

Imagery is one of the essential means to construct images and give readers sensory stimulation in poetry directly. Images and symbols have always been the soul of poetry. Poets in all ages, in all countries and in all languages have employed these devices to enhance their expression and create an impact on the reader [1]. The moon imagery is one of the most used imageries in Chinese and Western poetry. Among the ancient Chinese poems, "Three Hundred Poems of the Tang Dynasty" has 96 poems mentioning the moon [2] There is no shortage of classics chanting the moon in Western poems. For example, famous poets such as Emily Dickenson and Percy Shelley described the moon in their poetry. Chinese and Western scholars focused on their respective local poetry texts for previous studies of the moon imagery. Most Chinese scholars focused on digging inward, investigating the relationship between the moon and ancient Chinese Confucianism, rituals, filial piety, and cultural roots. Correspondingly, the study of the moon's imagery of foreign scholars mainly focused on their local works, such as dramas, novels, or ancient Roman and Greek poetry analysis. So far, few English articles analysed the application of the moon imagery in ancient Chinese poems. Meanwhile, there are very few studies comparing the moon imagery in
Chinese and Western poems. However, Chinese and Western poets' love for the moon imagery is similar, and there are many similarities and comparisons between them. This comparison can help us to deeply explore the differences between Chinese and Western cultural connotations and values. Therefore, based on the classic Chinese and Western poems, this study will compare and analyze the emotional and thematic connotations of the moon imagery, the expression techniques, the rhetorical devices, and the language characteristics of the moon imagery description in both Classical Chinese and Western poems. Furthermore, the study explores and understands the deep reasons behind Chinese and Western moon imagery differences.

\section{METHODOLOGY}

The main methods involved in this research are literary analysis method and comparison method.

\subsection{Literary analysis method}

This article refers to a large number of poetry works and academic works, such as " China and West: Comparative Poetics and Translatology (2nd Edition),"

" Introduction to the comparison between Chinese and Western Cultures," and also cited literary publications from "Poetry Journal" and related papers. In terms of 
poetry selection, this article discusses classic moon poems in both Chinese and English poetry, such as " The Midautumn Festival Tune: Prelude to Water Melody " by Sushi, "Drinking Alone under the Moon" by Libai, "To The Moon" by Percy Shelley, "The Moon And The Yew Tree" by Sylvia Plath. The comparison aims to study the different understandings of moon imagery in Chinese and Western poetry and its reasons.

\subsection{Comparison method}

Among the poems selected above, this article mainly compares the poems from four aspects: the connotation and theme of the moon imagery, the poetry expression techniques, the rhetorical devices, and the language characteristics.

\section{RESULTS}

\subsection{Comparison of connotation and theme of the moon imagery in Chinese and Western classic poems}

\subsubsection{The primary thematic connotation of the moon imagery in Chinese and Western classic poems}

In Chinese and Western poems, the moon imagery has been given a unique theme and connotation through thousands of years of poetry writing. It is imagery full of rich sentimentality.

In Chinese poetry, the appearance of the moon imagery is often accompanied by the catharsis of the poet's emotions. Over time, the moon imagery is given a feeling of loneliness and sorrow, which can be summarized as two kinds of emotional content: longing and frustration

1) The longing in this context generally refers to missing relatives and friends. In the poems addressed to friends, the longing the moon carries is sympathy, the rejoice of finding a confidant, and a farewell reluctance. Li Bai's " To Wang Changling banished to the west " wrote two sentences--" I'm sending my deep concerns to you through th' bright moon, to go all westards to the ancient Yeah-long state." (translaed by Xu Yuanchong) straightforwardly express the worries about the relegation of his dear friend. The longing and worries are handed to the moon, following his best friend as he moves far away. In the poems to the relatives, the moon embodies the people's sorrow away from home and the longing for their relatives. In " The Midautumn Festival Tune: Prelude to Water Melody", (translated by Lin Yutang) Su Shi addressed the separation and reunion of people by the change of the moon. The poem proposed the rhetorical question, "Shine upon our parting, reunion deny?" with a firm tone. The emotional question condensed the inability to meet relatives during the mid-autumn festival. At the end of the poem, Su Shi exhorted and comforted himself with "I only pray our life be long, and our souls together heavenwards fly!" expressing his longing and blessings for his relatives through the moon. It can be seen that in the two poems mentioned above, Chinese poems focus on the moon's ability to express the feelings of longing across space. Regardless of how far away a friend or relative is from the poet, poets share the same moon with them. The moon imagery is used as a medium to convey emotions. When looking up to the moon, they wish their relatives or friends could receive the poets' longingness.

2) The frustration integrated into the moon imagery is more of the poet's emotional venting, difficulty in fulfilling their ideals, loneliness, and helplessness after not being appreciated or understood. When expressing frustration, poets often use more obscure forms of expression. For example, in "Farewell to uncle Yun, imperial librarian, at Xie Tiao's pavilion in Xuan Zhou"(translated by $\mathrm{Xu}$ Yuanchong) Li Bai's moon is full of pride, and the image of frustration is not apparent, "Up to the moon in the blue sky." However, concerning the theme and background of the poem, the moon imagery expresses the frustration after the poet's talents and ideals have not been unappreciated. The poem mainly writes about sadness, and the moon represents the nobility and ideals in the poet's heart. Under the sad tone, the moon reflects the poet's frustration and loneliness. Li Shangyin's "To One Unnamed"(translated by $\mathrm{Xu}$ Yuanchong) writes, "At night you will feel cold while I croon by moonlight," through the cold tones of the moonlight, it hints that the poet's career is unsuccessful and his will is depressed. Li Bai's "Drinking Alone under the Moon"(translated by $\mathrm{Xu}$ Yuanchong) sentence "I raise my cup to invite the Moon who blends, her light with my shadow and we're three friends" used the moon to write the ultimate sense of loneliness. In the poem, there is always only the poet himself but nobody else. However, Li Bai cleverly used personification, and his shadow under the moonlight, to fill the initially empty picture all at once, creating an unreal sense of fullness and bringing out the emptiness of the picture. It reflects the loneliness of the poet's heart and the emotion that no one understands or appreciates him.

Unlike Chinese poems with moon imagery, Western poems have more diversified themes, connotations and moon imagery expresses a variety of subjects. They can be roughly classified into three categories: praising love, addressing the philosophy that things are changing in the world, and praising the moon.

1) Different From the Chinese eulogizing family affection, the moon is more closely related to love in Western poetry. In the second stanza of "Will You Come," the poet wrote, "If the night/Has a moon,/Full 
and bright?/O, will you come?" The stanza addresses scenery and expresses the idea that the poet wished to enjoy such scenery with their lover, directly indicating their affection and expectation of their lover. In "With how sad steps, O moon," the poet draws on moon imagery to write about lovesickness between lovers. The poet used "wan face" and "silently" to describe the moon, laying the foundation for a sad atmosphere, and then wrote, "What may it be that even in heavenly place/That busy archer his sharp arrows tries?" quoting an allusion from the Greek myth, Cupid, saying Even the moon high in the sky will be trapped by love. The whole poem uses the moon's shape to express the poet's hardships in pursuing love.

2) Moon imagery is also used in poems that address the philosophy that everything changes in the world. For example, in Shelley's "To the Moon," Shelley uses the moon to express the changing characteristics of everything in the world. Shelley described the moon as tired and lonely. Finally, the poet asked the moon, "And ever changing, like a joyless eye/That finds no object worth its constancy?" These two sentences bluntly explained the moon's periodic change implying that everything in the world is constantly seeking and constantly changing.

3) For poems praising the moon, "The Moon was but a Chin of Gold" uses gorgeous words to describe the moon from different angles. The poem writes, "Her Forehead is of Amplest Blonde-/Her Cheek-a Beryl hewn-/Her Eye unto the Summer Dew." The line above introduces natural and artificial things to describe the shape of the moon in the sky. In addition, the poem purely focuses on the moon itself, praising the moon. The poem constantly makes the moon more three-dimensional and refined through descriptions from different angles, without addressing other themes, philosophy, or expressing plenty of emotion.

\subsubsection{The characteristics of the moon imagery in Chinese and Western classic poems}

In addition to the content mentioned above, the connotation of the moon imagery in China and the West also has different characteristics.

1) Whether the moon imagery and other imageries appear simultaneously is also different in Chinese and Western poetry. In Chinese poetry, the moon imagery rarely appears alone, and other imageries usually appear together with the moon. Take " Song of the Bright Moon Reprise " as an example. The poem describes the cloud, and the jade rabbit, laurel tree, and toad related to ancient Chinese myths while writing about the moon. In addition to the moon imagery, the image of the poem is diverse and complex, and the images create a delicate picture. In "The Midautumn Festival Tune: Prelude to Water Melody," the moon appears with the sky, the cathedral fantasies, and the actual building. In these poems, the moon is the prominent imagery, and most of the other imageries that accompany the moon play a role in setting off the beauty and form of the moon, making the whole picture more detailed and more realistic. Compared with Chinese poetry's Sophisticated and complex picture, Western poetry has relatively fewer imageries to accompany the moon. In "A Hymn to the Moon," the whole poem is only about the moon with no second imagery. Therefore, the author focused more on the shape of the moon itself and depicting a vivid moon. The moon imagery in Western poetry does not have more imageries to set off and constitute a complete picture. However, it tends to focus on the expression of the poet's emotions and the description of the moon itself. For example, "With how sad steps, O moon" reveals emotions through the moon and lyrics, focusing on throwing questions to express the author's emotions. While " The Midautumn Festival Tune: Prelude to Water Melody" throws questions and uses more intentions to construct a complete picture.

2) The dynamic and static of the moon imagery are different. The moon in Chinese poetry often appears dynamically. In "The Midautumn Festival Tune: Prelude to Water Melody," the moon turns around the pavilion, stops by the window, and is cloudy and sunny. The moon in the poem is active, and the moon's movement also implies the flow of time, which promotes the emotional paving of the poem. The moon in "Drinking Alone under the Moon" is even more active. The moon is "invited" by the poet to drink, and it wanders in the night sky then leaves when the poet is drunk. The dynamics of the moon are vibrant. In terms of dynamics, moon imagery in Western poetry differs from Chinese poetry. Western poetry usually uses static details to describe the moon. The angle of description changes while the position of the moon remains unchanged. The second and third stanza in Emily Dickenson's "The Moon was but a Chin of Gold" writes:

Her Forehead is of Amplest Blonde-

Her Cheek-a Beryl hewn-

Her Eye unto the Summer Dew

The likest I have known-

Her Lips of Amber never part-

But what must be the smile

Upon Her Friend she could confer

Were such Her Silver Will-

The poet writes about the moon from multiple angles. The poet's perspective of description and observation of the moon is changing, but the state and position of the moon remain unchanged. Therefore, Western poetry presents a moon with a simple picture structure. 
3) There are also many differences in the moon imagery's shape, color, and luster. The moon's color is primarily bright and cold in Chinese poetry, and there is no specific color expression. In most Chinese poems, the moon appears as a "bright moon." A Tranquil Night," " The Midautumn Festival Tune: Prelude to Water Melody," and " Night on the surrendered city hearing the flute " are good examples. Although the moon is bright in the three poems, the moonlight in " The Midautumn Festival Tune: Prelude to Water Melody" uses "shadow" to profile the moonlight; in the other two poems, "A Tranquil Night" and " Night on the surrendered city hearing the flute " compares moonlight to frost. Despite the bright moon in Chinese poetry, the moonlight is cold, and the connotation is miserable. On the contrary, the moon in Western poetry is more diversified in color, and the words used by poets to describe the moon are also approximately "colors" that we are familiar with. In Emily Dickenson's "The Moon was but a Chin of Gold," the moon's color is blonde and amber, while in Shelley's poem, the moon is pale. In addition, the moon in Western poems can also be ruddy or blue. The diversification of the moon's color in Western poetry comes from the poet's different feelings in it, the situation, and the season. Compared with Chinese poems, the moon imagery is used in Western poetry on broader scenes and more diverse emotions, so the moon is described with more colors.

\subsection{Comparison of the expression techniques of the moon imagery in Chinese and Western classic poems}

In terms of expression techniques, there are also significant differences between Chinese and Western poetry. Chinese poetry tends to embody emotions in the scenery and is less likely to reveal the poet's thoughts and emotions straightforward. In contrast, Western poetry tends to express ideas directly and clarify emotions and thoughts in the poem.

The emotional expression of Chinese poetry is based on the characteristics of "freehand brushwork" in Chinese poetry, and the sense of picture created by the stacking of imageries expresses the poet's feelings. " The Midautumn Festival Tune: Prelude to Water Melody " writes, "She rounds the vermilion tower, Stoops to silk-pad doors, Shines on those who sleepless lie" constructing a picture of the low-altitude moon shining on the insomnia poet. The poet did not write what he thought or felt. However, the loneliness of having no accompany during the festival and the suffering of being unable to reunite have been perfectly integrated into the situation. Compared with the graceful and restrained expressions of Chinese poetry, the expression techniques of Western poetry are more direct. In "Will You Come," the poet directly uses "will (would) you come" as the first two sentences of each stanza to express their expectations for his lover; at the end of each stanza, he raises the question again and directly calls his lover "beautiful" and "beloved." Compared with the poet's emotion directly expressed in the poem, the moon imagery is only a tiny part of the poet's expression. Compared with Chinese poetry, which embodies emotions in the scenery, relying on the moon imagery and the created picture scene, the moon imagery of Western poetry is relatively separated from the emotion expressed in the poem. Therefore, the expression of emotions tends to be straightforward.

\subsection{Comparison of Rhetorical devices of Moon Imagery in Chinese and Western Classic Poems}

In terms of rhetoric, Chinese and Western poetry are similar. The rhetoric of the moon imagery mainly focuses on metaphor(simile) and personification.

1) Metaphor(simile). In Chinese poetry, the most classic metaphors are almost all from Li Bai. The simile in "Song of the Bright Moon Reprise" and the metaphor in "A Tranquil Night" respectively compare the moon to a white jade plate and frost. The metaphors in the two poems highly represent the image of the moon in the hearts of the Chinese people: white, cold, with a sad emotional tone. The metaphors in Western poems are diverse. Shelley compares the moon to "changing eyes" in his "To the Moon," and T. E. Hulme compares the moon to "a blushing farmer" in his "Autumn". The metaphor of the moon in Western poetry is not only based on the characteristics of its color but also focuses on the moon in different periods and shapes. Therefore, the metaphor is also very diverse and imaginative.

2) Personification. Both Chinese and Western poetry also use personification techniques to give the moon personality and express emotion by the personified moon. However, the treatment of personification in Chinese and Western poetry is slightly different. Chinese poetry uses personification to sublimate secular emotions to universal emotions that trace the philosophy of life. In contrast, the use of personification in Western poetry serves to express the poet's personal emotions. In "The Midautumn Festival Tune: Prelude to Water Melody," the poet uses personification to ask the moon, "Shine upon our parting, reunion deny ?" to extend the sorrow of the poet himself to a broader range of people's thoughts. The personification in "Drinking Alone under the Moon" regards the moon as a friend who drinks with him. However, the poet writes that "The Moon does not know how to drink her share;" expands the poet's loneliness into a sadness that no one understands, which arouses the sympathy of more readers. The subtle personification expression of Chinese poetry concretizes and universalizes the indescribable emotions, transforming the poet's own emotions into universal emotions and philosophical thoughts that most readers can share. On the contrary, the use of personification in 
Western poetry is focused on the poet's lyricism: Western poets are confiding to the moon. In "With how sad steps, O moon," the poet asked the moon, "Those lovers' scorn whom that love doth possess? Do they call virtue their ungratefulness?" The background and the poet's personal experience will make the verse challenging to understand. Although this kind of personification application does not achieve the purpose of sublimating emotions like Chinese poetry, it can better express the poet's emotions and make the lyricism more intense.

\subsection{Comparison of the language characteristics of the moon imagery in Chinese and Western classic poems}

The language characteristics of Chinese and Western poems when describing the moon are also quite different. Chinese poetry is concise, graceful and subtle, and focuses on lyricism; Western poetry is longer and straightforward and expresses philosophical logical speculation and narration.

In "The Midautumn Festival Tune: Prelude to Water Melody," Su Shi wrote, "She rounds the vermilion tower, Stoops to silk-pad doors, Shines on those who sleepless lie, Why does she, bearing us no grudge, Shine upon our parting, reunion deny?" In the first half-sentence, the poet describes the change in the position of the moon. Six words briefly describe the complicated movement of the moon from above the attic to the window, and the last three words concisely describe the picture of the moon shining on the poet in the middle of the night. The content of the words highly condensed the description of the scene, reflecting the concise characteristics of Chinese poetry. In the second half of the sentence, the poet asked the moon, "Why does she, bearing us no grudge, Shine upon our parting, reunion deny?" One question contains the periodic changes of the moon, the parting, and the longing of relatives, but the poet did not reveal his own emotions. The poet only implicitly expresses with questions, seemingly complaining about the moon but revealing his feelings.

Sylvia Plath's "The Moon and the Yew Tree" and Shelley's "To the moon" highly reflect the language characteristics of Western poetry. The whole poem of "The Moon and the Yew Tree" has 28 lines, and the third section contains the description of the moon in the night sky. It is also about the changes of the moon.

The moon is my mother. She is not sweet like Mary.

Her blue garments unloose small bats and owls.

How I would like to believe in tenderness -

The face of the effigy, gentled by candles,

Bending, on me in particular, its mild eyes.
The author does not hesitate to use many paragraphs to describe the moon's gentle light, compare the moon to a mother, and describe the gaze of "her," describing the shape of the moon in detail. In "To the moon," Shelley asked the moon, "And ever-changing, like a joyless eye/That finds no object worth its constancy?" directly asked the question in the author's mind, expressing the philosophical idea that things in the world are constantly changing.

\section{DISCUSSION}

It can be seen from the above that Chinese poetry and Western poetry share standard features but possess more significant differences. Those differences are primarily due to the two's different historical and cultural backgrounds, ideological concepts, and artistic aesthetics.

Chinese poetry's euphemistic and implicit characteristics are closely related to the traditional Chinese culture of Confucianism, Buddhism, and Taoism. In terms of the themes of poetry, Chinese Confucianism emphasizes the idea of " To cultivate the moral self, regulate the family, maintain the state rightly and make all peaceful" and marriage ethics, making it difficult to become mainstream for themes related to young love. Chinese moon poems rarely describe pre-marital love but express the longingness between relatives and couples, or lament the unsuccessful career. The literary criticism thought of " the golden mean" deeply influenced Chinese poetry creation. In addition, Taoism emphasizes "Words not being able to convey the meaning, catching the meaning while forgetting the words" and Buddhism concentrates on the pursuit of the ultimate state of "enlightenment" by Buddhists meditating themselves. [3] As a result, Chinese poets usually do not express all their views or ideas. More Readers are required to appreciate the meaning and develop their understanding of poetry. In terms of language, Chinese poetry is short and delicate. "Origin of Chinese characters," writes, "Poetry is will," which shows that poetry is the expression of the poet's will. The expression and explosion of human feelings are short-lived, and poetry produces this short-lived explosion. [3] Thus Chinese poetry is concise. Ancient Chinese poems all have the requirements of rhythm, and most of them limit the number of words to a small number, which also laid the foundation for the shortness of Chinese poetry. In addition, the characteristics of Chinese hieroglyphs have also established a strong sense of intuition in Chinese poetry and the Chinese people's habit of constructing pictures.

Compared with the limitation of the theme of Chinese moon imagery poetry, the diversification and daring to express in Western poetry are linked to free and open literary concepts. The mainstream Western literature mainly depicts the love between men and 
women, and the speculation on philosophical issues has been an essential cultural composition of the West since ancient Greece. Therefore, the themes of Western poetry are more diversified, involving many areas and themes that are not covered by Chinese poetry. Western civilization originated from marine civilization. Long-term trade and ocean exploration have formed the character of daring to express and the adventurous spirit. Compared with the introverted collectivist culture in China, Western culture pays more attention to individual expression, which naturally forms the characteristic that Western poets tend to express themselves and their ideas in their poems directly. The narrative characteristic of Western poetry has been buried in the soil of Western culture since the earliest epics. For example, the emergence of the foundational work "Homer's Epic" is a story told in poetry. [3] Therefore, Western poetry possesses a narrative style, and its length is also longer than Chinese poetry. In addition, the influence of Aristotle's "imitative theory" that "the art of beauty is the art of imitation" has contributed to the description features of western poetry. The sense of logic comes from Aristotle, Plato and other ancient Greek philosophers' pursuit of logic. Furthermore, Western words were not hieroglyphs. Most of them are composed of closely logical roots and affixes that closely affect the thinking mode of Westerners, making Western poetry respect a single realistic aesthetic and pay attention to formal logic.

\section{CONCLUSION}

This article discusses the differences and common points of the moon imagery in Chinese and Western poetry, from the connotation of the moon imagery, the poem's theme, the poet's expression techniques, rhetoric devices, and language characteristics. Based on these results, a comparative study was conducted in the context of Chinese and Western cultures, and the deeper cultural origins were explored. Literature and poetry are naturally included as exchange topics following frequent cultural exchanges between China and the West. Studying classic poetry about the moon imagery is just a pathfinder. We can place our vision on a broader world and compare Chinese and Western poetry and even literary works to gain a glimpse of the differences between Chinese and Western literature and cultures, and further to help people better understand and strengthen the communication between the two. In addition, this study also has limitations. In the selection of poems, this study only selected a few classic poems as the research subjects. The samples are not extensive enough to cover all the characteristics of Chinese and Western poems. It is expected that more extensive and in-depth research can be conducted in the later period.

\section{REFERENCES}

[1] N. Tiwari, Imagery and Symbolism in TS Eliot's Poetry, Atlantic Publishers \& Dist, 2001.

[2] $\mathrm{Z}$. $\mathrm{Hu}$, The moon image in western and Chinese literature, Journal of Hubei Normal University, vol. 02, Hubei, 2005, pp. 34-38, DOI:https://CNKI:SUN:HBSX.0.2005-02-009.

[3] Z. Gu, Introduction to the comparison between Chinese and Western Cultures, Peking University Press, 2007.

[4] Z. Gu, China and West: Comparative Poetics and Translatology (2nd Edition), Tsinghua University Press, 2010.

[5] S. Ge, A brief analysis of moon imagery in Li Bai's and Shakespeare's writing, Heilongjiang science and technology information magazine, vol. 15, Heilongjiang, 2009, pp. 134, DOI: :https:// CNKI:SUN:HLKX.0.2009-15-135.

[6] Q. Hu, On Su Shi's Poetic Imagery of the Moon, Journal of Southern Vocational Education, vol. 02, Guangdong, 2012, pp. 6-11, DOI:CNKI:SUN:NFZJ.0.2012-01-003.

[7] R.B. Antosh, Sun, Moon, and Stars: Cosmic Imagery in Michel Tremblay's Works, Dalhousie French Studies, Dalhousie University, vol. 57, Nova Scotia, 2001, pp. 116-27, DOI: http://www.jstor.org/stable/40836947.

[8] T. Parkinson, The sun and the Moon in Yeats's Early Poetry, The University of Chicago Press, vol. 50, Chicago , 1952, pp. 50-58, DOI: https://doi.org/10.1086/388937.

[9] E. G. Shtyrlina, M. Y. Antropova, Semantics of the artistic image of the moon in K. Balmont's poetry, Amazonia Investiga, vol. 7, pp. 233-238, DOI: https://amazoniainvestiga.info/index.php/amazonia/ article/view/549.

[10] J. Zeng, A Comparison of Moon Images in Kokinshu and in Tang-Dynasty Poems, Shanghai International Studies University, vol. 01, Shanghai, pp. 75-79, DOI: :https://CNKI:SUN:WYXY.0.2003-01-013.

[11]B. Shahnavazi, H. Jadidoleslami, A COMPARATIVE AND ANAIYTIC COMPARISON OF THE VARIOUS IMAGES OF MOON AND THE SUN BASED ON ANCIENT ASTRONOMY IN NASER KHOSRO, ANVARI AND NEZAMI'S POEMS, Malaysian Journal of Languages and Linguistics, vol. 07, Malaysia, pp. 40-50,

DOI: https://doi.org/10.24200/mjll.vol7iss1pp40-50. 
[12] X. Ren, The Moon Description in Both Chinese and English Lyrics, Sichuan International Studies University, vol. 04, Chongqing, 2007, pp. 166-169, DOI: :https://CNKI:SUN:CQGS.0.2007-04-038.

[13] Y. Song, X. Wang, On the Difference of Lyrical techniques between Chinese and Western Poetry from the image of "moon" -- Yan Wei's Answer to Liu Changqing's Re-Delivery under the Moon at The Opu Bridge and Huershoff's Moonrise as examples, Youth Literator, vol. 27, Helilongjiang, 2020, pp. 114-115, DOI: :https:// CNKI:SUN:QNWJ.0.2020-27-043.

[14] Y. Huo, A comparative study of classical Chinese and western love poetry, Journal of Chifeng University, vol. 32, Chifeng, 2011, pp. 114-115, DOI:

https://10.13398/j.cnki.issn1673-2596.2011.05.003. 